\title{
Gamma-irradiation induced modifications in structural and magnetic properties of nanocrystalline $\mathrm{Mn}_{0.5} \mathrm{Zn}_{0.5} \mathrm{Sm}_{\mathrm{x}} \mathrm{Fe}_{2-\mathrm{x}} \mathrm{O}_{4}$ ceramics
}

\author{
A.V. Anupama ${ }^{\text {a,b }}$, R. Kumar ${ }^{\mathrm{a}}$, H.K. Choudhary ${ }^{\mathrm{a}}$, V. Jagadeesha Angadi ${ }^{\mathrm{c}}$, H.M. Somashekarappa ${ }^{\mathrm{d}}$, \\ B. Rudraswamy ${ }^{\mathrm{e}}$, B. Sahoo ${ }^{\mathrm{a}, *}$ \\ ${ }^{a}$ Material Research Center, Indian Institute of Science, Bangalore, 560012, India \\ ${ }^{\mathrm{b}}$ School of Physical Sciences, REVA University, Bengaluru, 560064, India \\ ${ }^{\mathrm{c}}$ Department of Physics, PC Jabin Science College, Hubballi, 580031, India \\ ${ }^{\mathrm{d}}$ Center for Application of Radioisotopes and Radiation Technology, Mangalore University, Mangalore, 574199, India \\ ${ }^{\mathrm{e}}$ Department of Physics, Bangalore University, Bangalore, Karnataka, 560056, India
}

A R T I C L E I N F O

\section{Keywords:}

Sm doped Mn-Zn ferrite

High energy $\gamma$-irradiation

Structure and magnetic properties

FTIR spectroscopy

Mössbauer spectroscopy

\begin{abstract}
A B S T R A C T
The changes in structure, infrared absorption and magnetic property of nanocrystalline $\mathrm{Mn}_{0.5} \mathrm{Zn}_{0.5} \mathrm{Sm}_{\mathrm{x}} \mathrm{Fe}_{2-\mathrm{x}} \mathrm{O}_{4}$ $(\mathrm{x}=0.01,0.03$ and 0.05$)$ ceramics were studied after different doses $(0,15$ and $25 \mathrm{kGy})$ of $\gamma$-irradiation. The samples were prepared by solution combustion route. We observed that up to the highest studied dose (25kGy) of $\gamma$-irradiation all the samples retain the cubic spinel $(\boldsymbol{F d}-\mathbf{3 m})$ structure as of the pristine samples, however, the lattice parameter decreases. Furthermore, we observed the metastability of Sm (and Mn) atoms at the octahedral sites. By $\mathrm{Sm}^{3+}$ doping the saturation magnetization of the pristine samples decreases, but the magnetic coercivity increases drastically, indicating enhancement of magnetic anisotropy. After $\gamma$-irradiation the magnetic anisotropy vanishes completely and the sample behaves super-paramagnetically with a small variation in saturation magnetization. Our results are important to understand the behavior and stability of the magnetic hardness created by $\mathrm{Sm}^{3+}$ doping in soft magnetic $\mathrm{Mn}-\mathrm{Zn}$ ferrite ceramics.
\end{abstract}

\section{Introduction}

The recent developments in data acquisition modules and measuring devices in neutron and synchrotron facilities, nuclear reactors and accelerators raise the problem of irradiation effects on electronic components. The satellites and space crafts are often exposed to cosmic radiation of high doses. The radiation may create defects, inhomogeneity and structural changes in materials (Hassan et al., 2013). The properties of nano-sized ferrites are often governed by the chemical composition and the synthesis technique (Millot et al., 2007; Ferreira et al., 2003). The properties can be further modified by radiant energy such as gamma radiation. Hence, interaction of $\gamma$-radiation with matter and the resulting property control is an important area of research (Rosen et al., 1993; Murthy et al., 1971; Standley, 1972; Sathishkumar et al., 2010; Özgür et al., 2009). In addition, the properties of the ferrites depend on the occupation and type of cation present at the octahedral and tetrahedral sites of the spinel structure. These property changes can be achieved by $\gamma$-irradiation (Hassan et al., 2013; Karim et al., 2010; Ahmed and Bishay, 2001; Latif et al., 2009; Eltabey et al., 2011a, 2011b; Gokov et al., 2009; Hemeda, 1994; Darwish and
Hameda, 1994; Hemeda and El-Saadawy, 2003). The changes produced in the materials due to $\gamma$-irradiation depend on the type of material (AngadiAnupama et al., 2017a) and the net dose absorbed by the materials (Angadi et al., 2017; AngadiAnupama et al., 2017b). In this work detailed structural and magnetic property modifications in $\mathrm{Sm}^{3+}$ doped $\mathrm{Mn}-\mathrm{Zn}$ ferrite ceramics $\left(\mathrm{Mn}_{0.5} \mathrm{Zn}_{0.5} \mathrm{Sm}_{\mathrm{x}} \mathrm{Fe}_{2-\mathrm{x}} \mathrm{O}_{4}\right)$ were studied after irradiation with different moderate doses $(0,15$ and $25 \mathrm{kGy})$ of high energy gamma radiation.

\section{Materials and methods}

Nanocrystalline $\mathrm{Mn}_{0.5} \mathrm{Zn}_{0.5} \mathrm{Sm}_{\mathrm{x}} \mathrm{Fe}_{2-\mathrm{x}} \mathrm{O}_{4}(\mathrm{x}=0.01,0.03$, and 0.05$)$ powder samples were synthesized by solution combustion method (Angadi et al., 2016a) using a mixture of fuels: urea $\left[\mathrm{NH}_{2} \mathrm{CONH}_{2}\right]$ and glucose $\left.\left[\mathrm{C}_{6} \mathrm{H}_{12} \mathrm{O}_{6}\right)\right]$ in the ratio $3: 2$. Pellets of $10 \mathrm{~mm}$ diameter and $2 \mathrm{~mm}$ thickness were prepared by pressing the powder at $5 \mathrm{ton} / \mathrm{cm}^{2}$ pressure. The irradiation experiments were carried out by a ${ }^{60} \mathrm{Co}-\mathrm{ra}-$ diation source at a rate of $\gamma$-dose of $9.5 \mathrm{kGy} / \mathrm{h}(1 \mathrm{~Gy}=1 \mathrm{~J} / \mathrm{kg})$. The total time of irradiations were 95 and $160 \mathrm{~min}$ leading to a total dose of 15 and $25 \mathrm{kGy}$, respectively. The sample codes S1, S3 and S5 were used

\footnotetext{
* Corresponding author.

E-mail address: bsahoo@iisc.ac.in (B. Sahoo).
} 
for the as-prepared (pristine) samples with $\mathrm{x}=0.01,0.03$ and 0.05 , respectively. The sample-codes IS1-15 (IS1-25), IS3-15 (IS3-25) and IS5-15 (IS5-25) were used for the corresponding samples after $15 \mathrm{kGy}$ (25 kGy) of $\gamma$-irradiation.

The pristine (non-irradiated) samples and the $\gamma$-irradiated-samples were characterized in detail at RT using X-ray diffraction (XRD), SQUID Magnetometry, Mössbauer spectroscopy and Fourier Transform Infrared (FTIR) spectroscopy. The XRD patterns were recorded in the $2 \theta$ range of $10-80^{\circ}$ (with step size of $\sim 0.02^{\circ}$ ) using $\mathrm{Cu}-\mathrm{K}_{\alpha}$ radiation $(\lambda=1.54 \AA$ ). The unit cell parameters like the lattice constants and the crystallite sizes were obtained by the analysis of the Rietveld refinement results using "FullProf" software (Rodriguez-Carvajal, 1990). The room temperature magnetization measurements were performed using the "PPMS-14T" SQUID-VSM. All the above samples were also characterized in detail by Mössbauer spectroscopy at RT with $a^{57}$ Co-source (Rh-matrix). The obtained Mössbauer spectra were least squares fit using the "NORMOS" computer program (Brand, 1987). The isomer shift values given in this report are with respect to the ${ }^{57} \mathrm{Co}$-source (Rhmatrix). The FTIR spectra of all the samples were recorded in the wave number range of $300-4000 \mathrm{~cm}^{-1}$ using "Agilent" FTIR spectrometer.

\section{Results and discussion}

Fig. 1 shows the Rietveld refined XRD patterns of the $\mathrm{Mn}_{0.5} \mathrm{Zn}_{0.5} \mathrm{Sm}_{\mathrm{x}} \mathrm{Fe}_{2-\mathrm{x}} \mathrm{O}_{4}$ pristine samples and the samples after $\gamma$-irradiation ( $15 \mathrm{kGy}$ and $25 \mathrm{kGy}$ ). Comparing the XRD patterns of all the pristine samples (Fig. 1 (a, d, g)) it is clear that the FWHM of the XRD peaks increased with increase in $\mathrm{Sm}^{3+}$ content in the samples, i.e., the crystallite size decreases, as observed earlier (Angadi et al., 2016a). The mass density also increases as heavier rare earth $(\mathrm{Sm})$ atoms are added (Table S1 (Electronic Supporting Information (ESI) file). After 15 and $25 \mathrm{kGy}$ of $\gamma$-irradiation the crystalline structure of the samples remains intact $(\boldsymbol{F d}-\mathbf{3 m})$, but the feature of the XRD peaks were changed. After $15 \mathrm{kGy}$ of $\gamma$-irradiation the base of the XRD peaks becomes broad (Fig. 1 (b, e, h)) indicating that the average crystallite size decreases but the strain in the lattice increases. Hence, the $\gamma$-radiation creates disorder in the spinel lattice of the samples. The Rietveld refined lattice parameters are given in Table S1. The lattice parameters were found to decrease after $\gamma$-irradiation, which was also observed earlier with low doses of $\gamma$ irradiation in pure Mn-Zn ferrite (without Sm-doping) powders (Naik et al., 2014, 2015). The shape of the XRD peaks indicates a distribution of particle sizes. A reasonably good fit to the peaks could not be obtained using only a single Voigt profile. In order to quantify the particle sizes, we have fit the (311) XRD peaks with two Gaussians (Fig. 2). The FWHM of the sharp peak provides the maximum average crystallite size and that of the broad peak provides the minimum average crystallite size. The obtained crystallite sizes using Scherrer's formula: $L=\mathrm{K} \lambda$ / $\beta \operatorname{Cos} \theta$, where $L$ is the crystallite size, $\mathrm{K}$ is the shape factor, $\beta$ is the FWHM of the peak at angle $2 \theta$ and $\theta$ is the Bragg angle (Cullity and Graham, 2008), are listed in Table S1.

It is now well established that after high dose $(50 \mathrm{kGy})$ of $\gamma$-irradiation $\mathrm{Mn}_{0.4} \mathrm{Zn}_{0.6} \mathrm{Fe}_{2} \mathrm{O}_{4}$ phase transforms mostly into crystalline $\mathrm{ZnFe}_{2} \mathrm{O}_{4}$ and $\alpha-\mathrm{Fe}_{2} \mathrm{O}_{3}$ along with amorphous $\mathrm{MnO}$ phase (AngadiAnupama et al., 2017a). In the presence of rare earth elements such as Sm and Gd, the transformation is modified (Angadi et al., 2016b). Hence, the content of Sm and Gd controls the phase transformation process and the resultant compound formation.

After $15 \mathrm{kGy}$ of $\gamma$-irradiation of the sample S1, the FWHM of the (311) peak (Fig. 2) becomes larger. The crystallite size and the lattice parameter both decrease in comparison to that of the pristine sample (Table S1). Hence, a low dose of ( $15 \mathrm{kGy}) \gamma$-irradiation creates disorder in the spinel ferrites. However, after $25 \mathrm{kGy} \gamma$-irradiation (sample IS125) the crystallite size and the lattice parameter, both increased in comparison to that of the (IS1-15) sample irradiated with a $\gamma$-dose of $15 \mathrm{kGy}$. But, the lattice parameter value is still below that of the pristine sample (S1). This observation indicates that, by increasing the $\gamma$-dose from $15 \mathrm{kGy}$ to $25 \mathrm{kGy}$ the sample becomes more crystalline and there may be a tendency of local phase transformation from one phase with lower lattice parameter to another with higher lattice parameter. It can be envisaged by considering earlier literature (AngadiAnupama et al., 2017a; Angadi et al., 2016b) that a higher $\gamma$-dose of $50 \mathrm{kGy}$ transforms the similar, $\mathrm{Mn}_{0.5} \mathrm{Zn}_{0.5} \mathrm{Fe}_{2} \mathrm{O}_{4}$ material mostly to crystalline $\mathrm{ZnFe}_{2} \mathrm{O}_{4}$ phase along with $\alpha-\mathrm{Fe}_{2} \mathrm{O}_{3}$ phase (and amorphous $\mathrm{MnO}$ phase) (AngadiAnupama et al., 2017a), however, $\mathrm{Mn}_{0.4} \mathrm{Zn}_{0.6} \mathrm{Fe}_{2}$ ${ }_{0.06} \mathrm{Gd}_{0.03} \mathrm{Sm}_{0.03} \mathrm{O}_{4}$ phase transforms mostly into crystalline $\mathrm{ZnFe}_{2} \mathrm{O}_{4}$ phase, along with crystalline $\alpha-\mathrm{Fe}_{2} \mathrm{O}_{3}$ phase and small quantity of $\mathrm{MnO}_{2}$
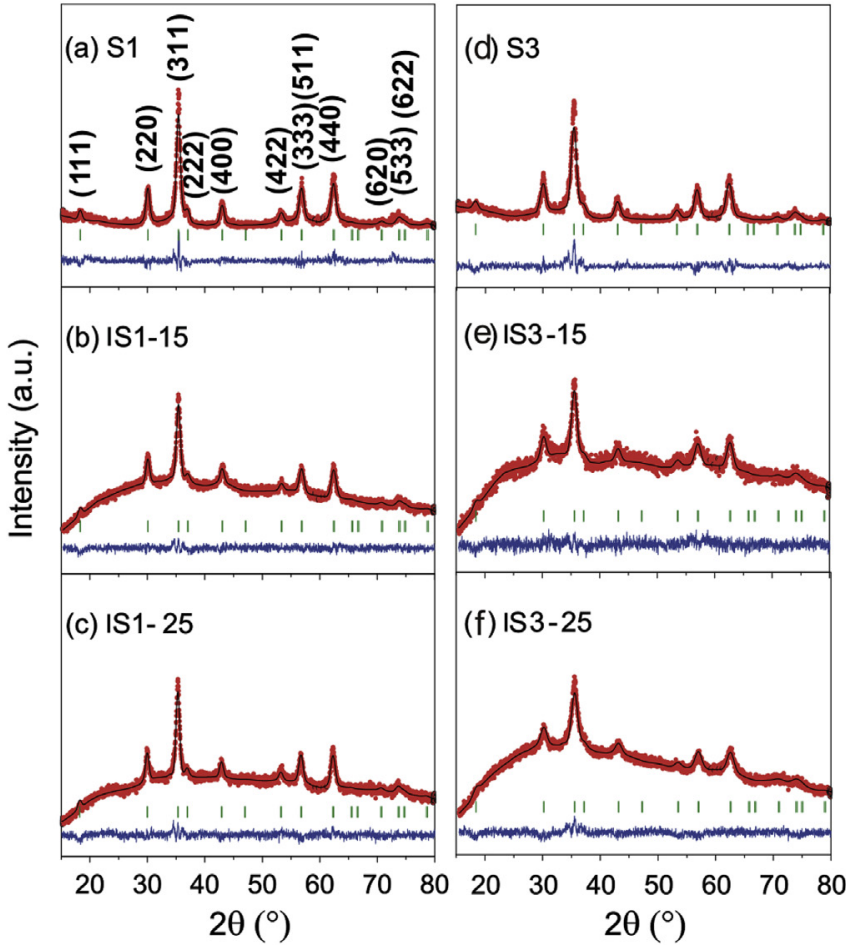

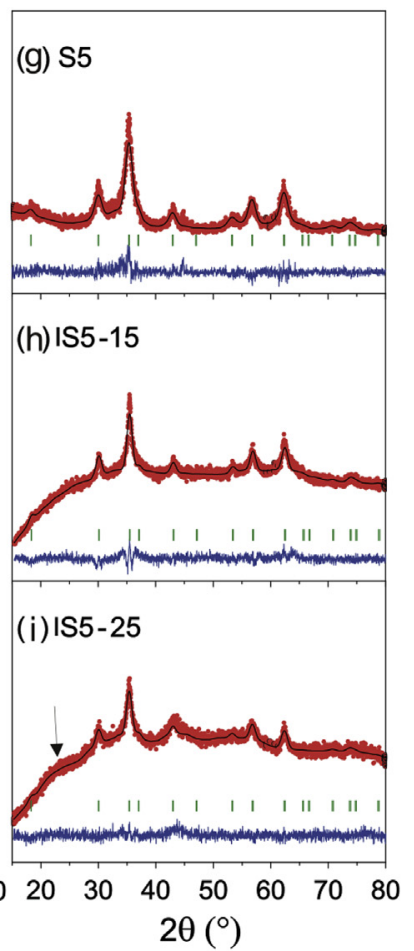

Fig. 1. The Rietveld refined XRD patterns for different compositions $(x)$ of the studied $\mathrm{Mn}_{0.5} \mathrm{Zn}_{0.5} \mathrm{Sm}_{\mathrm{x}} \mathrm{Fe}_{2-\mathrm{x}} \mathrm{O}_{4}$ samples. Top panel: pristine (un-irradiated) samples with $\mathrm{x}=0.01$ (S1) (a), $x=0.03$ (S3) (d), and $x=0.05$ (S5) (g). Middle panel: samples gamma irradiated with a dose of $15 \mathrm{kGy}$ for compositions, $\mathrm{x}=0.01$ (IS115) (b), $x=0.03$ (IS3-15) (e), and $x=0.05$ (IS515) (h). Lower panel: samples gamma irradiated with a dose of $25 \mathrm{kGy}$ for compositions, $\mathrm{x}=0.01$ (IS1-25) (c), $x=0.03$ (IS3-25) (f), and $x=0.05$ (IS5-25) (i). All the indexed Bragg positions in (a) are indexed corresponding to the cubic spinel phase, which are valid for the other XRD patterns too. The marked arrow ( $\downarrow$ ) in (i) at $\sim 2 \theta=22^{\circ}$, infers to the position of the $\mathrm{MnO}_{2}$ (Pnam) (110) reflection. 

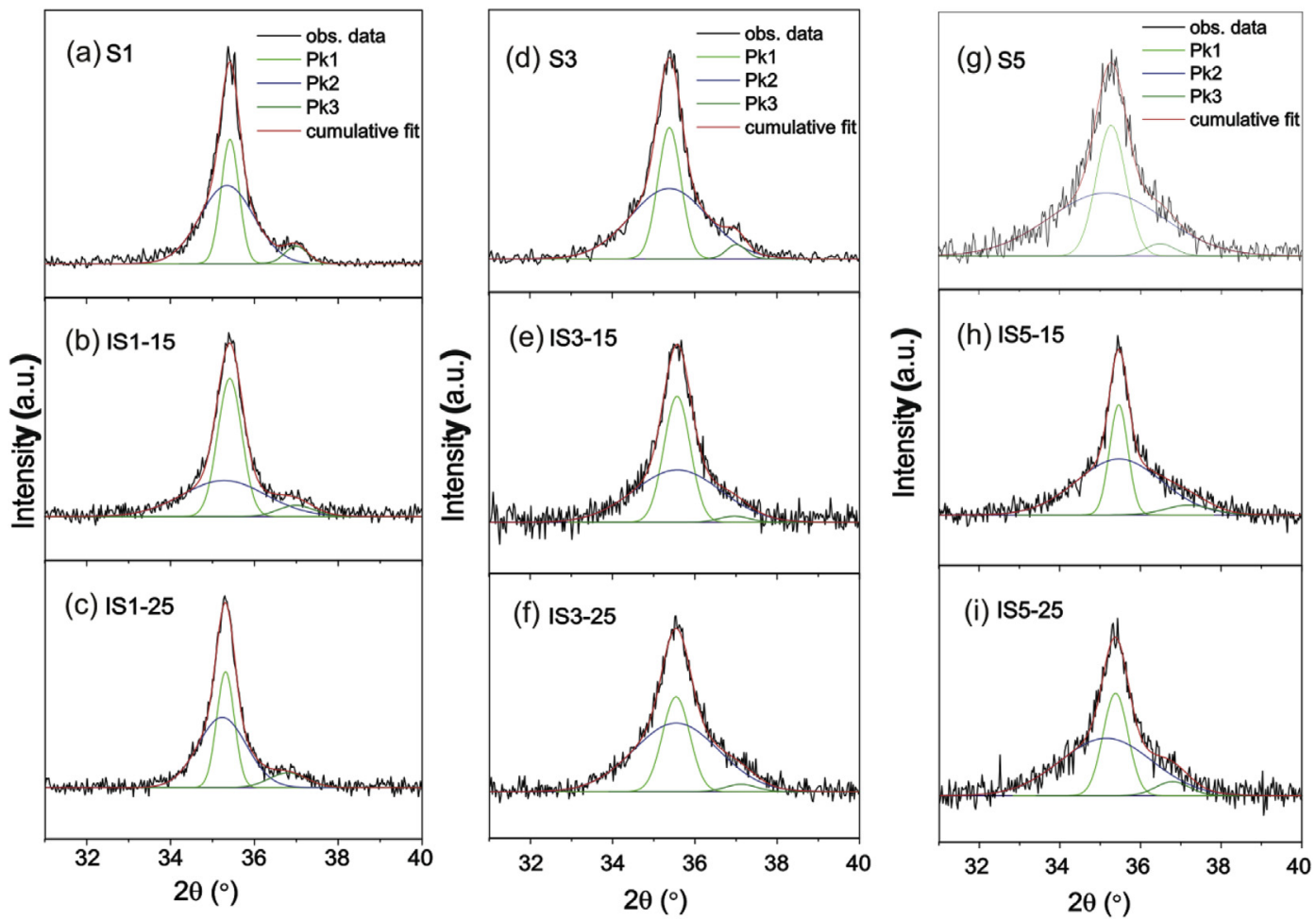

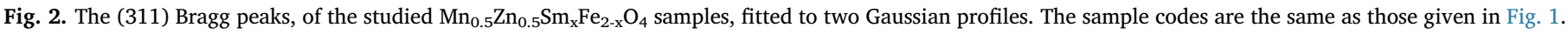
The low intensity (222) peak due to this spinel structure is also included in the fittings.

phase (Angadi et al., 2016b). In both the cases $\mathrm{ZnFe}_{2} \mathrm{O}_{4}$ is the major phase observed after $50 \mathrm{kGy}$ dose of $\gamma$-irradiation. As the present sample is similar to the above samples, we do expect that the present sample should also transform similarly with $\mathrm{ZnFe}_{2} \mathrm{O}_{4}$ as the major product phase. An irradiation dose of $25 \mathrm{kGy}$ might initiate the formation of $\mathrm{ZnFe}_{2} \mathrm{O}_{4}$ phase. To strengthen our assumption further, it is worth noting that we do not observe any major change in the position of the XRD peaks as the structure of $\mathrm{ZnFe}_{2} \mathrm{O}_{4}$ is also spinel. Again, the lattice parameter of pure $\mathrm{ZnFe}_{2} \mathrm{O}_{4}$ is higher than any of the $\mathrm{Mn}-\mathrm{Zn}$ ferrite spinel phase. So, it is notionally correct that the observed lattice parameter for the sample irradiated with $25 \mathrm{kGy}$ is higher than that of the sample irradiated with a dose of $15 \mathrm{kGy}$. Hence, the sample IS1-25 is the transient state before formation of $\mathrm{ZnFe}_{2} \mathrm{O}_{4}$ phase.

Under different doses of $\gamma$-irradiation, we have observed similar behavior for the lattice parameter of the sample S3 (Fig. 2 (d, e, f)) as that of the sample S1, except that the crystallite size decreases (FWHW increases) continuously as the $\gamma$-irradiation dose increases. In the high dose $\gamma$-irradiation study of similar materials, namely, $\mathrm{Mn}_{0.4} \mathrm{Zn}_{0.6} \mathrm{Fe}_{2-}$ ${ }_{0.04} \mathrm{Gd}_{0.02} \mathrm{Sm}_{0.02} \mathrm{O}_{4}$ and $\mathrm{Mn}_{0.4} \mathrm{Zn}_{0.6} \mathrm{Fe}_{2-0.02} \mathrm{Gd}_{0.01} \mathrm{Sm}_{0.01} \mathrm{O}_{4}$ samples, both transform to $\mathrm{ZnFe}_{2} \mathrm{O}_{4}$ (along with $\alpha$ - $\mathrm{Fe}_{2} \mathrm{O}_{3}$ ) after $50 \mathrm{kGy}$ of $\gamma$-irradiation, however, the latter compound $\left(\mathrm{ZnFe}_{2} \mathrm{O}_{4}\right)$ shows broader $\mathrm{XRD}$ lines (more disorder and smaller particle size (Angadi et al., 2016b)). Hence, for our present sample S3 after $\gamma$-irradiation we should expect broad lines in comparison to S1. Hence, the observed decrease in crystallite size with increasing $\gamma$-irradiation dose in sample S3 is rational.

The XRD pattern of the sample S5 after $\gamma$-irradiation showed a different behavior than that of the other two studied samples (S1 and S3) (Fig. 2). But, the present material (sample S5) is similar to the $\mathrm{Mn}_{0.4} \mathrm{Zn}_{0.6} \mathrm{Fe}_{2-(0.06)} \mathrm{Gd}_{0.03} \mathrm{Sm}_{0.03} \mathrm{O}_{4}$ sample (with rare earth substitution of $\mathrm{x}=0.06$ ). In this material, $\mathrm{S} 5$, formation of crystalline $\mathrm{MnO}_{2}$ (Pnam) as major product phase and $\mathrm{ZnFe}_{2} \mathrm{O}_{4}$ as minor phase, was observed after $50 \mathrm{kGy}$ of $\gamma$-irradiation (Angadi et al., 2016b). Hence, we expect the phase transformation in S5 to proceed with the tendency to form $\mathrm{MnO}_{2}$, unlike in the case of S1 and S3 where the major expected phase is $\mathrm{ZnFe}_{2} \mathrm{O}_{4}$ after $50 \mathrm{kGy}$ of $\gamma$-irradiation. We may consider that when the rare earth $(\mathrm{Sm})$ atoms leave the spinel lattice, it gives rise to the relatively sharper peak for the stress-relaxed $\mathrm{ZnFe}_{2} \mathrm{O}_{4}$ phase. For higher dose (25 kGy) of $\gamma$-irradiation (sample IS5-25) the formation of $\mathrm{MnO}_{2}$ phase dominates and the (311) peak becomes broad before diminishing to the extent of the contribution from a small amount of $\mathrm{ZnFe}_{2} \mathrm{O}_{4}$ phase as observed earlier (Angadi et al., 2016b). However, the sharper peak for the IS5-15 sample (Fig. 2(h)) in comparison to that of S5 and IS5-25 samples (Fig. 2(g) and (i), respectively) suggests that the $\mathrm{MnO}_{2}$ formation (as observed after $50 \mathrm{kGy} \gamma$-irradiation (Angadi et al., 2016b)) proceeds through the formation of amorphous $\mathrm{MnO}_{2}$ phase after $25 \mathrm{kGy}$ of $\gamma$-irradiation.

In order to understand the observed reduction of the lattice parameter with $\gamma$-irradiation dose, we have analyzed the occupancy of the Sm and Mn atoms through the "Fullprof" software. We observed that the vacancies of the Sm and Mn-sites in the spinel structure lead to decrease in the lattice parameter and the unit cell volume. Hence, we conclude that the Sm atoms are initially (and then Mn atoms at higher doses) came out of the tetrahedral/octahedral sites in the unit cells where these atoms were occupied, before the spinel unit cell is damaged and the other phases, like $\mathrm{MnO}_{2}$ and $\mathrm{ZnFe}_{2} \mathrm{O}_{4}$ etc., were formed at higher $\gamma$ irradiation doses as observed earlier (AngadiAnupama et al., 2017a, 2017b; Angadi et al., 2017).

Effective pinning of the Fe spins at the Sm sites (which acts as a paramagnetic defect centre in the Mn-Zn ferrite crystal) introduces magneto-crystalline anisotropy in these materials (Angadi et al., 2016a). Hence, the coercivity of the virgin materials increases with increasing Sm-content (Fig. 3). However, the low magnetic interaction and ordering of the Sm atoms with $\mathrm{Fe} / \mathrm{Mn}$ atoms reduces the saturation magnetization with increasing Sm-doping. Hence, with increasing ' $\mathrm{x}$ ' in $\mathrm{Mn}_{0.5} \mathrm{Zn}_{0.5} \mathrm{Sm}_{\mathrm{x}} \mathrm{Fe}_{2-\mathrm{x}} \mathrm{O}_{4}$ (pristine) samples the saturation magnetization is decreasing, but the coercivity is increasing.

After $\gamma$-irradiation we have observed a small variation in the saturation magnetization values of the samples (Fig. 3). In sample S1, the $\mathrm{M}_{\mathrm{s}}$ value $(18.7 \mathrm{emu} / \mathrm{g}$ ) decreases after $15 \mathrm{kGy}$ of $\gamma$-irradiation, while it increases after $25 \mathrm{kGy}$ of $\gamma$-irradiation. For the IS1-15 sample, it seems 

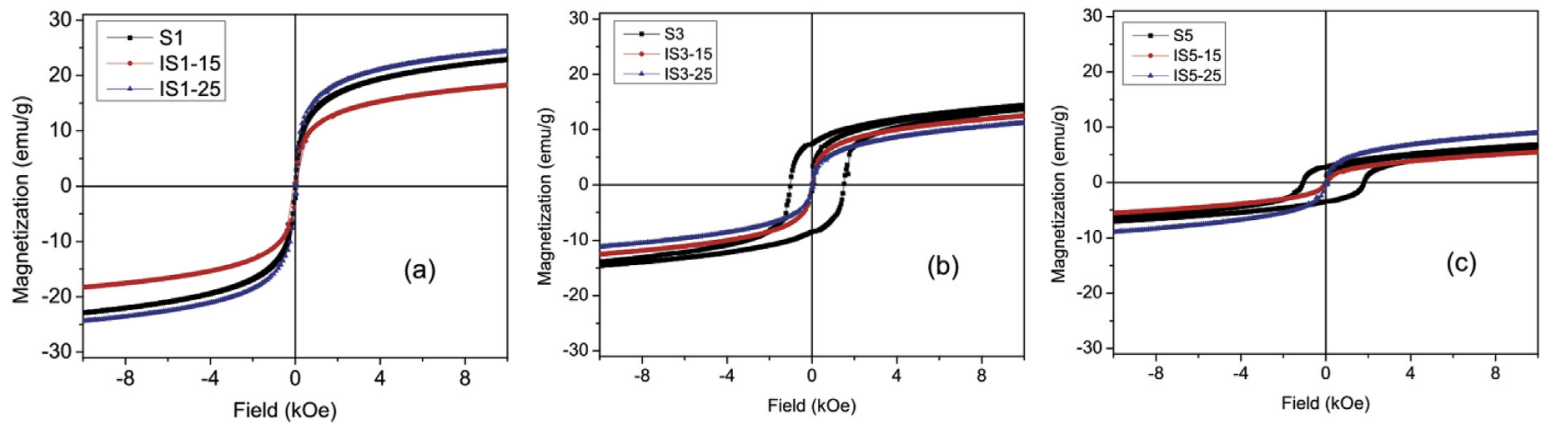

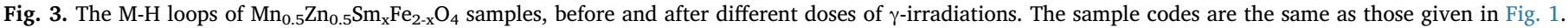

that the disorder (observed as increased FWHM of the XRD peaks, decreased particle size) caused due to $\gamma$-irradiation reduces the saturation magnetization in the sample to $14.1 \mathrm{emu} / \mathrm{g}$. Furthermore, after $25 \mathrm{kGy}$ of $\gamma$-irradiation dose (sample IS1-25), the cation disorder (i.e., Zn atoms at the octahedral site at this transient state of phase transformation to $\mathrm{ZnFe}_{2} \mathrm{O}_{4}$ ) might be the reason for the higher saturation magnetization (20.3 emu/g). All the samples (S1, IS1-15 and IS1-25) behave superparamagnetically.

For the S3, IS3-15 and IS3-25 samples the disorder increases with the $\gamma$-irradiation dose, as observed via the increase in the FWHM of the XRD peaks (Fig. 2(d, e, f)). This increase in disorder might also be leading to the observed decrease of saturation magnetization (Table S2). Interestingly, after $\gamma$-irradiation the coercivity of the sample S3 reduces to about zero (Fig. 3(b)). This suggests that $\gamma$-irradiation can be used to tune the coercivity (magnetic hardness) of the materials. Moreover, it seems that the $\mathrm{Sm}$ atoms do not play any role in providing magnetic anisotropy (and coercivity) after $\gamma$-irradiation (the IS3-15 and IS3-25 samples). This observation suggests that $\mathrm{Sm}$ atoms are the first to come out of the spinel lattice of the samples making the material soft ferromagnetic even at this low dose of $15 \mathrm{kGy}$.

For the sample S5, which shows further low saturation magnetization but higher coercivity, the coercivity reduces to zero after $\gamma$-irradiation (Fig. 3(c)). This also suggests that $15 \mathrm{kGy}$ of $\gamma$-irradiation is high enough for the Sm (bigger rare earth) atoms to come out of the spinel lattice confirming their high metastable nature. Interestingly, for these samples (after $\gamma$-irradiation, IS5-15 and IS5-25), like the other samples, the variation of the saturation magnetization scales with disorder of the spinel (Mn-Zn ferrite) phase.

The Mössbauer spectra of all the studied samples are shown in Fig. 4. All the samples give rise to similar spectra consisting of a broad doublet. The presence of paramagnetic defects, like Sm-atoms and the non-magnetic $\mathrm{Zn}$-atoms in the $\mathrm{Mn}_{0.5} \mathrm{Zn}_{0.5} \mathrm{Fe}_{2-\mathrm{x}} \mathrm{Sm}_{\mathrm{x}} \mathrm{O}_{4}$ samples are responsible for the low hyperfine field of the Mössbauer spectra (Angadi et al., 2016a). All the spectra were fit using a crystalline doublet and a broad sextet distribution. The Mössbauer spectral parameters obtained from the fitting are given in Table S3. Considering the isomer shift (IS $\approx 0.24 \mathrm{~mm} / \mathrm{s}$ ) and the quadrupole splitting ( $Q S \approx 0.50 \mathrm{~mm} / \mathrm{s}$ ) values of all the studied samples, the central crystalline doublet in all the respective spectra is assigned to the $\mathrm{ZnFe}_{2} \mathrm{O}_{4}$ type of local regions in the sample (Upadhyay et al., 2001; Rath et al., 2002), which is paramagnetic in nature. After gamma irradiation the corresponding area of this doublet decreases suggesting that there is a tendency for the formation (precipitation) of $\mathrm{ZnFe}_{2} \mathrm{O}_{4}$ phase in all the samples, which maybe a more stable phase than $\mathrm{Mn}-\mathrm{Zn}$ ferrite, under $\gamma$-irradiation. The hyperfine field distribution $\mathrm{P}\left(\mathrm{B}_{\mathrm{hf}}\right)$ of the sample $\mathrm{S} 1$ shows the dominant peak at $B_{h f}=4.5 \mathrm{~T}$ and a few small intensity peaks at higher $B_{h f}$ values (Fig. 4(a), right). The higher $B_{h f}$ peaks are absent in sample S3 and S5. This proves the weak magnetic ordering in S3 and S5 samples than in S1 sample. This supports the decrease of saturation magnetization with increasing Sm-content in the samples, as observed in Fig. 3.

After $\gamma$-irradiation of sample S1, the sample IS1-15, shows a bit improved magnetic ordering as the higher $\mathrm{B}_{\mathrm{hf}}$ peaks in $\mathrm{P}\left(\mathrm{B}_{\mathrm{hf}}\right)$ (Fig. 4(b), right) are more intense than that for sample S1. However, in sample IS1-25, the intensity of the higher $B_{h f}$ peaks decreases. This observation is in line with the XRD results that IS1-15 sample is more disordered (higher FWHM) compared to that of the S1 sample. However, the higher saturation magnetization for IS1-25 sample (Fig. 3(a)) might be due to a partial $\mathrm{Zn}^{2+}$ cation occupation at the octahedral site, which is not observed in the Mössbauer spectrum in Fig. 4(c). For samples S3, IS3-15 and IS3-25, there is a monotonous decrease of the superparamagnetic contribution (area of the sextet distribution) in the Mössbauer spectrum. This agrees well with the decrease in coercivity and saturation magnetization (Fig. 3(b)) with increasing doses of the $\gamma$ irradiation. The superparamagnetic nature of the sample can also be inferred from the fact that the FWHM of the XRD peaks were found to increase with increasing dose of $\gamma$-irradiation (Fig. 2(d, e, f)). The
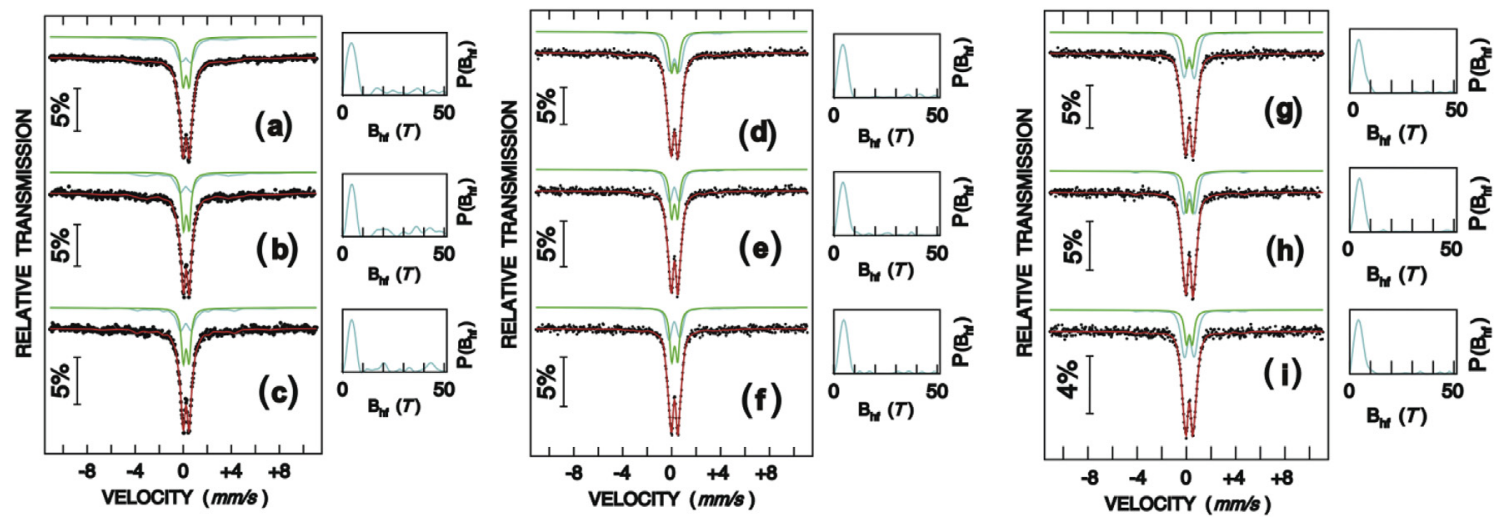

Fig. 4. The Mössbauer spectra of the $\mathrm{Mn}_{0.5} \mathrm{Zn}_{0.5} \mathrm{Sm}_{\mathrm{x}} \mathrm{Fe}_{2-\mathrm{x}} \mathrm{O}_{4}$ samples, before and after different doses of $\gamma$-irradiations: (a) S1, (b) IS1-15, (c) IS1-25, (d) S3, (e) IS3-15, (f) IS3-25, (g) S5, (h) IS5-15 and (i) IS5-25. 

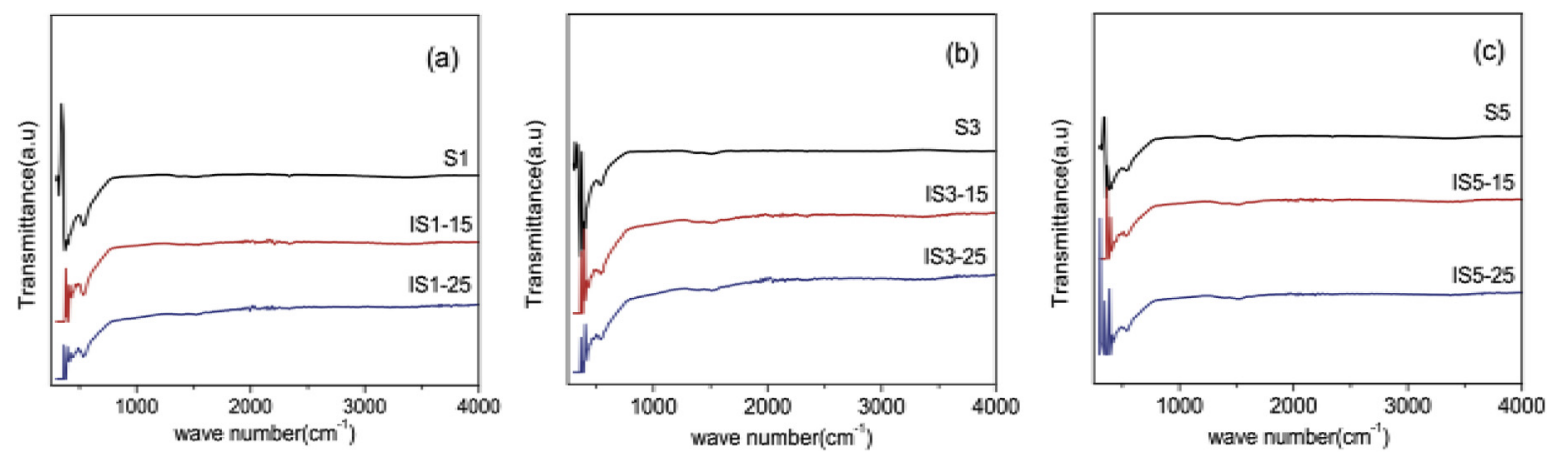

Fig. 5. The FTIR spectra of the $\mathrm{Mn}_{0.5} \mathrm{Zn}_{0.5} \mathrm{Sm}_{\mathrm{x}} \mathrm{Fe}_{2-\mathrm{x}} \mathrm{O}_{4}$ samples, before (S) and after (IS) different doses of $\gamma$-irradiations. The spectra are shifted vertically for clarity. The sample codes are the same as those given in Fig. 1.

coercivity of the sample S5 reduced to zero after $\gamma$-irradiation, but the saturation magnetization of IS5-15 is a bit lower and that of IS5-25 is a bit higher, as discussed above. The area (Table S3) under the superparamagnetic contribution (sextet distribution) in Fig. 4 (g, h, i) varies similarly. This observed variation can be rationalized with the observed trend in the variation of the FWHM of the disordered (XRD) peaks in Fig. 2 (g, h, i) and the saturation magnetization (Fig. 3(c)).

The FTIR spectra of all the studied samples are shown in Fig. 5. The two absorption bands corresponding to the vibrations of the tetrahedral $\left(\nu_{1} \sim 540-580 \mathrm{~cm}^{-1}\right)$ and octahedral $\left(\nu_{2} \sim 350-400 \mathrm{~cm}^{-1}\right)$ site cations were observed (Angadi et al., 2016a). This confirms the retention of the spinel ferrite phase of the samples even after $25 \mathrm{kGy}$ of $\gamma$-irradiation, which agrees well with the XRD results. However, the octahedral band of the $\gamma$-irradiated samples appear weak in comparison to that of the pristine samples. This indicates that $\gamma$-irradiation favors the removal of octahedral site ions (mainly Sm and partially $\mathrm{Mn}$ ) and indicates the presence/formation of $\mathrm{ZnFe}_{2} \mathrm{O}_{4}$ phase.

\section{Conclusions}

The pellets of Sm-doped $\mathrm{Mn}_{0.5} \mathrm{Zn}_{0.5} \mathrm{Fe}_{2} \mathrm{O}_{4}$ samples were exposed to high energy $\gamma$-irradiation of different doses (0, 15 and $25 \mathrm{kGy})$. The change in structure and magnetic properties of these samples were studied in detail and compared with earlier results. We conclude that up to $25 \mathrm{kGy}$ of $\gamma$-irradiation the studied samples retain their spinel structure as observed by XRD. However, the observed lattice parameter after $\gamma$-irradiation are less than that observed for the pristine samples. This decrease in lattice parameter might be due to the shrinkage of the unit cell after removal of Sm and Mn atoms from their respective lattice sites by the $\gamma$-irradiation. The $\gamma$-irradiation creates defects/vacancies in the spinel structure which was observed as broadening of the FWHM of the XRD peaks and reduction in FTIR absorption intensity of the octahedral band. The exhibition of the superparamagnetic behavior, transformation of the material from relatively hard magnetic nature to soft magnetic nature and reduction in area of the magnetic hyperfine field in the Mössbauer spectra are the consequence of the $\gamma$-irradiation induced defect/vacancy creation. The structural and magnetic property transformations at low doses of $\gamma$-irradiation are envisaged as an intermediate state of the transformation of the samples, which generally transforms to crystalline $\mathrm{ZnFe}_{2} \mathrm{O}_{4}, \mathrm{MnO}_{2}$ and $\alpha-\mathrm{Fe}_{2} \mathrm{O}_{3}$ phases at higher doses $(\sim 50 \mathrm{kGy})$ of $\gamma$-irradiation. Our investigations explore the structural stability and degradation behavior of ferrites, which will help in predicting the performance of the ferrite-based devices used near intense radiation sources and in spacecrafts.

\section{Declaration of competing interest}

The authors declare no conflict of interest.

\section{Acknowledgements}

The authors (JAV and BR) are thankful to the UGC, New Delhi, for the financial support received through the Major Research project (File No.UGC-MRP-41-946). RK is thankful to CSIR, New Delhi (File No. 09/ 079(2634)/2014-EMR-I) for financial support received through Senior Research Fellowship. The work at IISc Bangalore was supported by the ISRO-IISc STC project (Code Number-ISTC/CMR/BS/355).

\section{Appendix A. Supplementary data}

Supplementary data to this article can be found online at https:// doi.org/10.1016/j.radphyschem.2019.108506.

\section{References}

Ahmed, M.A., Bishay, S.T., 2001. Conductivity improvement of Li-Co-Yb ferrite. J. Phys. D Appl. Phys. 34, 1339-1345.

Angadi, V.J., Anupama, A.V., Kumar, R., Matteppanavar, S., Rudraswamy, B., Sahoo, B., 2016a. Observation of enhanced magnetic pinning in $\mathrm{Sm}^{3+}$ substituted nanocrystalline $\mathrm{Mn}-\mathrm{Zn}$ ferrites prepared by propellant chemistry route. J. Alloy. Comp. 682, 263-274.

Angadi, V.J., Anupama, A.V., Kumar, R., Somashekarappa, H.M., Praveena, K., Rudraswamy, B., Sahoo, B., 2016b. Evidence of structural damage in Sm and Gd codoped Mn-Zn ferrite ceramics due to high-energy gamma irradiation. Ceram. Int. 42, 15933-15939.

Angadi, V.J., Anupama, A.V., Kumar, R., Somashekarappa, H.M., Matteppanavar, S., Rudraswamy, B., Sahoo, B., 2017. Dose dependent modifications in structural and magnetic properties of gamma-irradiated nanocrystalline $\mathrm{Mn}_{0.5} \mathrm{Zn}_{0.5} \mathrm{Fe}_{2} \mathrm{O}_{4}$ ceramics. Ceram. Int. 43, 543-546.

Angadi, V.J., Anupama, A.V., Kumar, R., Choudhary, H.K., Matteppanavar, S., Somashekarappa, H.M., Rudraswamy, B., Sahoo, B., 2017a. $\gamma$-radiation induced structural and morphological transformation in nanocrystalline Mn-Zn ferrite ceramics. Mater. Chem. Phys. 199, 313-321.

Angadi, V.J., Anupama, A.V., Choudhary, Harish K., Kumar, R., Somashekarappa, H.M., Mallappa, M., Rudraswamy, B., Sahoo, B., 2017b. Mechanism of gamma-irradiation induced phase transformations in nanocrystalline $\mathrm{Mn}_{0.5} \mathrm{Zn}_{0.5} \mathrm{Fe}_{2} \mathrm{O}_{4}$ ceramics. J. Solid State Chem. 246, 119-124.

Brand, R.A., 1987. Improving the validity of hyperfine field distributions from magnetic alloys: Part II: polarized source and spin texture. Nucl. Instrum. Methods B 28, 417-432.

Cullity, B.D., Graham, C.D., 2008. Introduction to Magnetic Materials, second ed. WileyIEEE Press.

Darwish, N.Z., Hameda, O.M., Abd El-Ati, M.I., 1994. Effect of ${ }^{60} \mathrm{Co} \gamma$-radiation damage on the structural and dielectric properties of Co-Zn ferrite. Appl. Radiat. Isot. 45, $445-448$.

Eltabey, M.M., Ali, I.A., Hassan, H.E., Comsan, M.N.H., 2011a. Effect of $\gamma$-rays irradiation on the structure and magnetic properties of $\mathrm{Mg}-\mathrm{Cu}-\mathrm{Zn}$ ferrites. J. Mater. Sci. 46, 2294-2299.

Eltabey, M.M., Ali, I.A., Hassan, H.E., Comsan, M.N.H., 2011b. Effect of $\gamma$-rays irradiation on the structure and magnetic properties of $\mathrm{Mg}-\mathrm{Cu}-\mathrm{Zn}$ ferrites. J. Mater. Sci. 46, 2294-2299.

Ferreira, T.A.S., Waerenborgh, J.C., M Mendonça, M.H.R., Nunes, M.R., Costaa, F.M., 2003. Structural and morphological characterization of $\mathrm{FeCo}_{2} \mathrm{O}_{4}$ and $\mathrm{CoFe}_{2} \mathrm{O}_{4}$ spinels prepared by a co-precipitation method. Solid State Sci. 5, 383-386.

Gokov, S.P., Gritsyna, V.T., Kasilov, V.I., Kochetov, S.S., Kazarinov, Y.G., 2009. Efficiency of defects formation in spinel under high energy electron and gamma beam irradiation. Atom. Sci. Technol. 52, 81-84.

Hassan, H.E., Sharshar, T., Hessien, M.M., Hemeda, O.M., 2013. Effect of $\gamma$-rays irradiation on Mn-Ni ferrites: structure, magnetic properties and positron annihilation 
studies. Nucl. Instrum. Methods Phys. Res., Sect. B 304, 72-79.

Hemeda, O.M., 1994. Electrical properties of the Co-Zn ferrites irradiated with $\gamma$-rays. Phase Transitions 51, 87-95.

Hemeda, O.M., El-Saadawy, M., 2003. Effect of gamma irradiation on the structural properties and diffusion coefficient in Co-Zn ferrite. J. Magn. Magn. Mater. 256, $63-68$.

Karim, A., Shisath, S.E., Shukla, S.J., Jadhav, K.M., 2010. Gamma irradiation induced damage creation on the cation distribution, structural and magnetic, properties in $\mathrm{Ni}$ Zn ferrite. Nucl. Instrum. Methods Phys. Res. B 268, 2706-2711.

Latif, A., Kh-ur-Rahman, M., Rafique, M.S., Bhatti, K.A., Imran, M., 2009. Irradiation effects on copper. Radiat. Eff. Defects Solids 164, 68-72.

Millot, N., Gallet, S.L., Aymes, D., Bernard, F., Grin, F., 2007. Spark plasma sintering of cobalt ferrite nanopowders prepared by coprecipitation and hydrothermal synthesis. J. Eur. Ceram. Soc. 27, 921-926.

Murthy, C.R.K., Likhite, S.D., Sastry, N.P., 1971. Low temperature magnetic hysteresis of fine particle aggregates occurring in some natural samples. Philos. Mag. 23, 503-507.

Naik, P.P., Tangsali, R.B., Meena, S.S., Bhatt, P., Sonaye, B., Sugur, S., 2014. Gamma radiation roused lattice contraction effects investigated by Mossbauer spectroscopy in nanoparticle Mn-Zn ferrite. Radiat. Phys. Chem. 102, 147-152. https://doi.org/10. 1016/j.radphyschem.2014.04.038.
Naik, P.P., Tangsali, R.B., Sonaye, B., Sugur, S., 2015. Radiation induced structural and magnetic transformations in nanoparticle $\mathrm{Mn}_{\mathrm{x}} \mathrm{Zn}_{(1-\mathrm{x})} \mathrm{Fe}_{2} \mathrm{O}_{4}$ ferrites. J. Magn. Magn. Mater. 385, 377-385. https://doi.org/10.1016/j.jmmm.2015.03.032.

Özgür, Ü., Alivov, Y., Morkoç, H., 2009. Microwave Ferrites, Part 2: passive components and electrical tuning. J. Mater. Sci. Mater. Electron. 20, 911-952.

Rath, C., Anand, S., Das, R.P., Sahu, K.K., Kulkarni, S.D., Date, S.K., Mishra, N.C., 2002 Dependence on cation distribution of particle size, lattice parameter, and magnetic properties in nanosize Mn-Zn ferrite. J. Appl. Phys. 91, 2211-2215.

Rodriguez-Carvajal, J., 1990. FULLPROF: A Program for Rietveld Refinement and Pattern Matching Analysis, Abstracts of the Satellite Meeting on Powder Diffraction of the XV Congress of the IUCr. Toulouse, France, pp. 127.

Rosen, N.R., Weidner, J.G., Boldt, H.D., Rosen, D.S., 1993. Prevention of transfusionassociated graft-versus-host disease: selection of an adequate dose of gamma radiation. Transfusion 93, 125-127.

Sathishkumar, G., Venkataraju, C., Sivakumar, K., 2010. Synthesis, Structural and dielectric studies of nickel substituted cobalt-zinc ferrite. Mater. Sci. Appl. 1, 19-24.

Standley, K.J., 1972. Oxide Magnetic Materials, second ed. Oxford Univ. Press.

Upadhyay, C., Verma, H.C., Rath, C., Sahu, K.K., Anand, S., Das, R.P., Mishra, N.C., 2001. Mössbauer studies of nanosize $\mathrm{Mn}_{1-\mathrm{x}} \mathrm{Zn}_{\mathrm{x}} \mathrm{Fe}_{2} \mathrm{O}_{4}$. J. Alloy. Comp. 326, 94-97. 